\title{
Forecasting the Economic Security Level of Murmansk Oblast as a Coastal Arctic Region
}

\author{
Roman V. Badylevich $\left.{ }^{1 *[O R C I D} 0000-0002-3164-8745\right]$
}

\author{
${ }^{1}$ Luzin Institute for Economic Studies - Subdivision of the Federal Research Centre "Kola Science Centre of the \\ Russian Academy of Sciences", Apatity, Murmansk Oblast, Russia \\ ramapatit@rambler.ru
}

\begin{abstract}
The article is devoted to the study of the potential impact of key factors that form long-term and medium-term scenarios of development of the coastal Arctic region on the level of economic security of the Murmansk Oblast. We highlight the specifics of implementation of medium- and long-term forecasting as a management function for the regional level. It is determined that within the framework of the forecasting of economic security it is vital not only to form a complete list of internal and external factors that determine socio-economic processes, but also to identify those factors and conditions that will have the strongest impact on the individual components of economic security. The study identifies the main groups of factors that will determine the development of the Murmansk Oblast in the medium and long term (environmental and nature-related, macroeconomic and market, technological, demographic, political, geopolitical, social). The impact of factors on the potential change in both the general fields that form the level of economic security of any subject of the Russian Federation and the specific fields that determine the economic security of coastal Arctic regions has been assessed. We established that the opportunities to increase the level of economic security of the Murmansk Oblast are connected with the increase in the region's ability to develop sustainably by improving the investment climate and development of the main sectors of the economy, as well as by improving transport infrastructure. The potential for negative demographic trends and difficulties for the largest mining companies in the region, caused by unfavorable market conditions and depletion of producing fields, determine security.
\end{abstract}

Keywords: economic security, regional policy, regional forecasting, coastal Arctic region, Murmansk Oblast

\section{INTRODUCTION}

Forecasting the development of the subject of the Russian Federation is the most important function in the system of regional management.

In a broad sense, forecasting at the level of the subject of the Russian Federation involves prospective anticipation of the development of the regional system or its individual components based on the identification of the factors that determine their dynamics.

Forecasting allows the authorities to determine the main objectives in the system of regional development management, to identify favorable and unfavorable trajectories of possible socio-economic development of the subject of the Russian Federation, to identify the main risks and threats to sustainable development.
Currently, considerable attention is paid to the methodology of forecasting implementation at the regional level. The stages of forecasting implementation have been extensively studied in the methodology of forecasting $[1,2]$.

In the case of the formation of medium- and long-term forecasts, the need to describe the conditions of external and internal environment, which will determine the main socio-economic processes and structural changes in the region, comes to the fore. In this case, it is particularly important to identify key factors that can have an impact on regional processes taking into account the specifics of the level of socio-economic development of the Russian Federation subject, its economic structure, specifics of territorial location and availability of various resources [3]. 
It should be noted that the calculation of forecast values of quantitative parameters of socio-economic development of the region cannot be the key task in medium- and long-term forecasting. This position is due to the multiplicity of various factors influencing the dynamics of the region's development indicators, which makes it virtually impossible to build a fullfledged forecast model of key indicators in the medium and long term [4].

One of the most important areas of implementation of forecasting of regional systems development is the forecasting of the dynamics of economic security level. Economic security of a region is the state of various spheres that determine the socio-economic position of a subject of the Russian Federation, ensuring sustainable development and a sufficient level of independence from the influence of external factors [5].

Forecasting the level of economic security of the regional system allows us to estimate the potential of socio-economic development of the subject of the Russian Federation [6], as well as the probability and scale of crisis situations in case of negative scenario conditions [7].

The importance of forecasting economic security increases significantly in conditions of high turbulence in the external environment, the emergence of new crisis phenomena and increased dynamism of fundamental factors affecting socioeconomic processes at various levels. These conditions require us to study the influence of factors and conditions on the level of economic security of the regions, which are significantly affected by the negative impact of macroeconomic phenomena due to the specifics of economic structure, specifics of territorial location and high dependence on the state of world resource markets. Such regions should include constituent entities of the Russian Federation that are fully or partially located in the Arctic Zone of the Russian Federation (ASRF) and have a coastal position. These regions, on the one hand, provide a significant part of the production of a variety of natural resources, making a significant contribution to the GDP of the country, and on the other hand, due to their unique spatial location, are of strategic importance in the system of national security [8].

The system of forecasting implementation for the Arctic coastal regions due to the uniqueness of their natural potential, increased importance for the regional economy of marine economic activity, territorial remoteness from the metropolitan subjects of the Russian Federation is specific, which makes the study of issues of assessment and analysis of factors and conditions for forming forecasts of the dynamics of the economic security level for such regions especially relevant.

\section{MATERIALS AND METHODS}

The purpose of this study is to assess the impact of key factors determining different scenarios of development of the coastal Arctic region on the state of its economic security.

In order to achieve the goal, the paper will address the tasks related to the analysis of the features of development of the Murmansk Oblast as a coastal Arctic region, identifying the main factors that determine the long-term scenarios of development of the region, and assessing their possible impact on the level of economic security of the Murmansk Oblast.

The methodological basis is formed by the studies of leading scientists in the field of forecasting the development of regional systems, as well as the author's earlier studies in the field of assessing regional economic security.

At the stage of identifying the main groups of factors determining the long-term development of the Murmansk Oblast, such scientific methods as generalization, classification, synthesis were applied. In order to identify the key factors, the results of a large-scale study conducted by scientists of the Kola Science Centre of the Russian Academy of Sciences were used, in which scenarios of the Murmansk Oblast development in the context of global changes in the Arctic were formed [9].

At the stage of assessing the impact of the identified factors on the dynamics of the level of economic security of the Murmansk Oblast, the expert method is applied, based on the survey of a group of scientists performing research within the project "Identification of problems and development of approaches to ensure economic security of the coastal Arctic regions in the new geopolitical conditions". The congruence of opinions of at least $75 \%$ of the total number of experts was accepted as the lower limit of significance of the influence of a particular factor on the components of economic security of the region.

The general (the region's ability for sustainable development, sustainability of the region's financial system, dependence of the economy on imports of major products, poverty and unemployment, scientific potential, quality of life, demographics, 
ecology) and specific areas (structure of the region's economy and place of industries related to maritime activities in the regional economy system, availability of transport infrastructure; increase in the cost of economic activity and life of the population) are identified as key components determining the level of economic security of the subject of the Russian Federation. The methodology for assessing the level of economic security of the coastal Arctic region was presented in detail by the author in a previously published paper [10].

\section{RESULTS}

\subsection{Key features of the Murmansk Oblast as a coastal Arctic region}

To identify the key factors that will determine the development of the state of the Murmansk Oblast in the mid- and long term, it is necessary to identify the specifics of socio-economic development of this subject of the Russian Federation.

Murmansk Oblast is a region located in the northwest of Russia that has a coastal position. The territory of the region is entirely in the Russian Arctic. The peculiarities of the spatial location of the region are its access to the ice-free Kola Bay of the Barents Sea, as well as its cross-border position.

The region is characterized by a fairly low population density (63rd place among the constituent entities of the Russian Federation) and a steady decline in the number of permanent residents in recent years due to both natural decrease and migration outflow. At the same time, the Murmansk Oblast is among the top ten regions in terms of personal income.

In the structure of the added value of the Murmansk Oblast the leading place belongs to such industries as agriculture, forestry, hunting, fishing and fish farming, mining (there are large enterprises of phosphate and iron ore mining), manufacturing (primarily, metallurgical and food production) and transport industry.

The consolidated budget of the Murmansk Oblast is deficient, however, in recent years the level of subsidies from the federal budget is relatively low.

The region is characterized by a high level of investment activity. For example, in terms of investment in fixed capital per capita, in 2020 the region was in the ninth place, which is rather high, also the Murmansk Oblast is among the top ten
Russian regions in terms of investment attractiveness.

Next, let us present the state of the areas determining the level of economic security of the Murmansk Oblast as a coastal Arctic region.

A specific feature of the economy of the Murmansk Oblast is specialization in the industries related to the coastal position of the region. Thus, the fishing and fish-farming industry accounts for more than $10 \%$ of the gross regional product.

There are three seaports (Murmansk, Kandalaksha and Vitino) in the Murmansk region, one of which is among the largest in the Northern Sea Route (located in the capital of the Kola region).Recently, the volume of traffic through the ports of the region has been increasing, and the infrastructure of the Murmansk seaport is being actively developed. The Murmansk Oblast is one of the few regions where the structure of the transport industry is dominated by sea transport. At the same time, the level of development of other modes of transport is not so high. In particular, the region is characterized by low density of public roads with hard surface, among the roads of the regional level the share of meeting modern normative requirements does not exceed 40\%.Despite a fairly high density of railways, many towns in the region are not connected by rail.

In the Murmansk region, there is a low manifestation of the factor of increasing the cost of economic activity and the life of the population as one of the parameters for assessing the level of economic security of the coastal Arctic region. The region is among the constituent entities located relatively close to the federal centers, which makes transport costs for doing business relatively low.

At the same time, the high average income level of the population partially compensates for the higher cost of goods and services for residents of the region. It should be noted that the Murmansk Oblast is characterized by high fuel consumption due to harsh climatic conditions.

\subsection{The main factors determining the state of economic security of the Murmansk Oblast in the long term}

Among the factors that can potentially affect the socio-economic processes and the level of economic security of the Murmansk Oblast, the following groups should be highlighted: 
1) Environmental and natural resource management factors

This group of factors is quite broad and includes, first of all, climatic changes affecting economic activity in the region and changes in the conditions of large enterprises of the sphere of extraction of mineral resources. Let us highlight several factors of this group which can have the most significant impact on the Murmansk Oblast:

- global warming;

- depletion of some major mineral deposits in the region;

- discovery of new deposits of mineral resources on the territory of the region, the extraction and processing of which will prove to be economically attractive in the conditions of technological development;

- increased environmental requirements;

- increasing negative impact of industrial production on the ecology of the Murmansk Oblast.

\section{2) Macroeconomic and market factors}

Macroeconomic and market factors will primarily affect the efficiency of extractive and manufacturing industries, the region's fiscal potential and the living standards of the Murmansk Oblast population. In this group, we identify the following medium- and long-term impact factors:

- demand and price levels for raw materials produced in the region (phosphate rock, iron ore, etc.)

- increased competition and higher demands for products in the markets of raw materials produced by large industrial structures of the region;

- activation of the state policy aimed at the development of small and medium-sized businesses, increasing the availability of credit resources, realization of the investment potential of the region;

- high inflation, rising prices for fuel and utilities;

- the emergence of new financial crises;

- intensification of the use of tools to improve the investment climate in the region, including through the creation of special economic zones, the provision of preferential conditions to large investors, the implementation of public-private partnership schemes.

\section{3) Technological factors}

The introduction of new technologies can affect both the development of the main economic sectors of the Murmansk Oblast and improve the quality of life of the population. The most likely factors in this group are:

- emergence and introduction of new mining and processing technologies;

- development of technologies and informatization processes in services, transport, communications and social spheres;

- increased emphasis on science and scientific development.

\section{4) Demographic changes}

In the medium and long term, demographic changes in the Murmansk Oblast can be influenced by the following factors:

- strengthening of national and regional policies aimed at improving the demographic situation;

- increasing differentiation of living standards of the population by regions;

- reduction in the need for labor force in the region (due to the introduction of new technologies, transition to rotational methods of development in the North, depletion of resource bases).

\section{5) Political factors}

Political changes will be manifested primarily in the increase/decrease of interest in the development of the Russian Arctic territories in general and the Murmansk region in particular, as well as changes in the intensity of contacts with the countries bordering the region. The most significant factors of this group include:

- maintaining the policy of confrontation with Western partners, intensification of sanctions from European countries and the U.S., orientation towards Asian markets;

- change of political power and revision of relations with Western countries;

- increased interest in Arctic research and development at the national level. 


\section{6) Geopolitical factors}

Among the most likely geopolitical factors that can affect the scenarios of development and the level of economic security of the Murmansk Oblast we highlight:

- increasing geopolitical tensions in international relations;

- the emergence of new and intensified existing disagreements on the zoning and border approval in the Arctic;

- the continued or increased impact of the pandemic on the intensity of economic processes, international movements and openness of borders;

- development of the Northern Sea Route.

\section{7) Social factors}

Among the social factors that can influence the development of the Murmansk Oblast we should highlight:

- increasing the educational level of the population;

- increasing the role of civil society and the level of social responsibility of business.

\section{DISCUSSION}

Let us assess the impact of the identified factors determining the forecasts of development of the Murmansk Oblast on the components of economic security of the region (Table 1).

Table 1. Influence of the factors determining the forecasts of development of the Murmansk Oblast on the components of economic security of the region

\begin{tabular}{|c|c|c|c|c|c|c|c|c|c|c|c|c|c|}
\hline 을 & Factors & 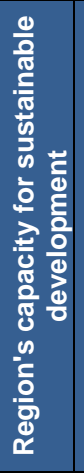 & 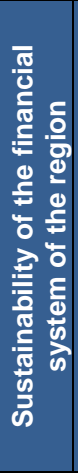 & 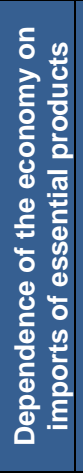 & 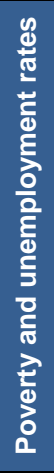 & 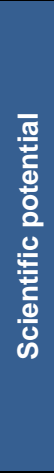 & 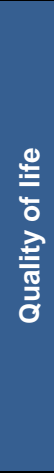 & $\begin{array}{l}\frac{8}{0} \\
\frac{0}{0} \\
\frac{0}{0} \\
\frac{0}{2} \\
\frac{0}{0}\end{array}$ & 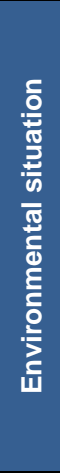 & 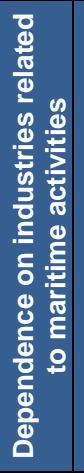 & 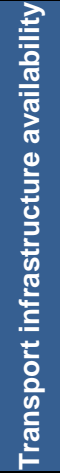 & 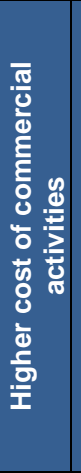 & $\begin{array}{l}\frac{5}{0} \\
\frac{1}{\alpha} \\
\frac{\alpha}{2} \\
\frac{1}{4} \\
z \\
\frac{1}{2}\end{array}$ \\
\hline \multirow{5}{*}{ 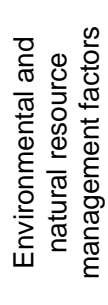 } & gradual warming & $\uparrow$ & & & & & & & & & & $\uparrow$ & +2 \\
\hline & depletion of large mineral deposits & $\downarrow$ & $\downarrow$ & & $\downarrow$ & & & $\downarrow$ & & $\downarrow$ & & $\downarrow$ & -6 \\
\hline & development of new resource deposits & $\uparrow$ & $\uparrow$ & & $\uparrow$ & & & & & $\uparrow$ & & & +4 \\
\hline & increased environmental requirements & & & & & & & & 个 & & & $\downarrow$ & 0 \\
\hline & $\begin{array}{l}\text { increased negative impact of industrial } \\
\text { production on the environment }\end{array}$ & & & & & & $\downarrow$ & $\downarrow$ & $\downarrow$ & & & & -3 \\
\hline \multirow{7}{*}{ 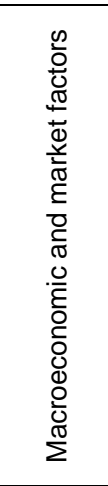 } & $\begin{array}{l}\text { increase in demand and the level of prices } \\
\text { for raw materials produced in the region }\end{array}$ & & $\uparrow$ & & $\uparrow$ & & & & & & & & +2 \\
\hline & $\begin{array}{l}\text { lower demand and price levels for raw } \\
\text { materials mined in the region }\end{array}$ & $\downarrow$ & $\downarrow$ & & $\downarrow$ & & & & & $\downarrow$ & & & -4 \\
\hline & $\begin{array}{l}\text { increased competition and higher product } \\
\text { requirements in raw material markets }\end{array}$ & $\downarrow$ & & & & & & & & & & $\downarrow$ & -2 \\
\hline & $\begin{array}{l}\text { intensification of the policy aimed at the } \\
\text { development of small and medium-sized } \\
\text { businesses }\end{array}$ & $\uparrow$ & & & $\uparrow$ & & & & & & & & +2 \\
\hline & high inflation, rising fuel and utilities prices & & & & $\downarrow$ & & & & & & & $\downarrow$ & -2 \\
\hline & the emergence of new financial crises & & $\downarrow$ & & $\downarrow$ & & & & & & & & -2 \\
\hline & $\begin{array}{l}\text { implementation of tools to improve the } \\
\text { investment climate in the region }\end{array}$ & & $\uparrow$ & & & & & & & & $\uparrow$ & & +2 \\
\hline \multirow{2}{*}{ 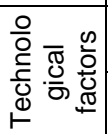 } & $\begin{array}{l}\text { emergence and implementation of new } \\
\text { mining and processing technologies }\end{array}$ & $\uparrow$ & & & & $\widehat{T}$ & & & & & & & +2 \\
\hline & $\begin{array}{l}\text { development of informatization } \\
\text { technologies in various spheres }\end{array}$ & & & & & & $\uparrow$ & & & & & & +1 \\
\hline
\end{tabular}




\begin{tabular}{|c|c|c|c|c|c|c|c|c|c|c|c|c|c|}
\hline & \begin{tabular}{|l} 
increased emphasis on science and \\
scientific development
\end{tabular} & & & & & $\uparrow$ & & & & & & & +1 \\
\hline \multirow{4}{*}{ 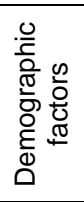 } & & & & & & & & & & & & & \\
\hline & $\begin{array}{l}\text { strengthening policies aimed at improving } \\
\text { the demographic situation }\end{array}$ & $\uparrow$ & & & & & $\uparrow$ & $\uparrow$ & & & & & +3 \\
\hline & \begin{tabular}{|l|l} 
increasing differentiation in living \\
standards of the population by regions
\end{tabular} & & & & & & $\downarrow$ & $\downarrow$ & & & & & -2 \\
\hline & $\begin{array}{l}\text { reduced need for labour force in the } \\
\text { region }\end{array}$ & & & & $\downarrow$ & & & $\downarrow$ & & & & & -2 \\
\hline \multirow{3}{*}{ 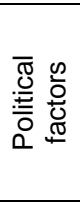 } & \begin{tabular}{|l|} 
maintaining a policy of confrontation with \\
Western partners
\end{tabular} & & & $\uparrow$ & & & & & & & & & +1 \\
\hline & $\begin{array}{l}\text { change of political power and review of } \\
\text { relations with Western countries }\end{array}$ & & & $\downarrow$ & & & & & & & & & -1 \\
\hline & $\begin{array}{l}\text { increasing interest in Arctic research and } \\
\text { development at the national level }\end{array}$ & $\uparrow$ & $\uparrow$ & & $\uparrow$ & & & & & & $\uparrow$ & & +4 \\
\hline \multirow{4}{*}{ 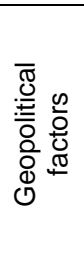 } & 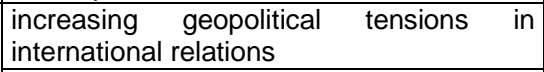 & & & & & $\downarrow$ & & & & & & & -1 \\
\hline & $\begin{array}{|lll|}\begin{array}{l}\text { increased disagreement } \\
\text { boundary setting }\end{array} & & \text { Arctic } \\
\end{array}$ & $\downarrow$ & & & & & & & & & & & -1 \\
\hline & \begin{tabular}{|l|} 
persistence or increasing impact of the \\
COVID-19 pandemic
\end{tabular} & & $\downarrow$ & & $\downarrow$ & & & & & & & & -2 \\
\hline & development of the Northern Sea Route & $\uparrow$ & & & $\uparrow$ & & & & & & $\uparrow$ & & +3 \\
\hline \multirow{3}{*}{ 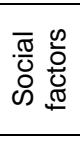 } & $\begin{array}{l}\text { improving the educational level of the } \\
\text { population }\end{array}$ & & & & & $\uparrow$ & & & & & & & +1 \\
\hline & $\begin{array}{l}\text { increasing the role of civil society and the } \\
\text { level of social responsibility of business }\end{array}$ & & & & & & $\uparrow$ & & & & & & +1 \\
\hline & FINAL IMPACT & +3 & 0 & 0 & -1 & +2 & +1 & -3 & 0 & -1 & +3 & -3 & \\
\hline
\end{tabular}

Source: Compiled by the authors

According to the data presented in the table, we see that the strongest positive impact on the level of economic security of the Murmansk Oblast in the medium and long term, as experts state, can be provided by industrial development of new resource deposits, increased interest in the study and development of the Arctic at the national level, intensified policy aimed at improving the demographic situation in the country in general and the Murmansk Oblast in particular, and the development of the Northern Sea Route.

At the same time, the following factors form the greatest risks when ensuring a sufficient level of economic security: depletion of large mineral deposits, reduced demand and price level for raw materials extracted in the region, increased negative impact of industrial production on the environment.

\section{CONCLUSION}

In the system of implementation of long-term forecasting of economic security of the Arctic coastal region, the central place is occupied by the identification of key factors that shape the development of the regional system and their potential change.

From the position of systematization of such factors it seems significant to classify them according to the sphere of application and character of impact (positive or negative).
The aggregate impact of the identified key factors allows us to form long-term scenarios of changes in the level of economic security of regional systems and possible trajectories of regional development.

The study identified the factors that can have the strongest positive impact on the level of economic security of the Murmansk Oblast in the medium and long term, as well as the factors that have the greatest risks.

It was established that the increase in economic security of the Murmansk Oblast will be promoted primarily by the factors influencing the development of extractive industries in the region (development of new industrial fields), as well as the factors determining the possibility of increasing the provision of the region with transport infrastructure (implementation of Arctic development programs at the federal level, increasing the interest and importance of transportation along the Northern Sea Route).

The main risks to the Murmansk Oblast's economic security are associated with the preservation and strengthening of negative demographic trends due to the difficult situation in the labor market and insufficient standard of living, as well as the decline in the efficiency of large industrial enterprises in the region, whose functioning can be significantly affected by the 
situation in world markets of raw materials, depletion of deposits under development and negative macroeconomic factors.

\section{ACKNOWLEDGMENTS}

The research was carried out within the RFBR grant 19-010-00159 A "Identification of problems and development of approaches to ensure economic security of the coastal Arctic regions in the new geopolitical conditions".

\section{REFERENCES}

[1] I.Y. Beletskaya, "Procedure script of forecasting at decision-making about strategy of progress of region", Scientific Journal of Belgorod State University [Nauchnye vedomosti Belgorodskogo gosudarstvennogo universiteta], Series: Economics. Informatics, 2011, vol. 1(96), pp. 5-14. (In Russ).

[2] G.N. Abramova, O.A. Krukova, "Forecasting of socio-economic development of regions under uncertainty" [Prognozirovanie social'noekonomicheskogo razvitiya regionov $\mathrm{v}$ usloviyah neopredelennosti], Journal of Public and Municipal Administration, 2016, vol. 2(21), pp. 39-43. (In Russ). DOI: 10.12737/20539

[3] P.A. Minakir, A.N. Demyanenko, "Regional scenario forecasting", Federalism, 2012, vol. 1(65), pp. 29-44. (In Russ.).

[4] N.N. Mikheeva, "Long-term forecasts of regional development: Analysis of results and the problem of development", Forecasting issues [Problemy prognozirovaniya], 2018, vol. 5(170), pp. 24-38. (In Russ.).

[5] E. Karanina, S. Alekseev, D. Loginov, "Sustainable development and economic security of the region", IOP Conference Series: Earth and Environmental Science, 2019, vol. 403, p. 012152. DOI: 10.1088/1755$1315 / 403 / 1 / 012152$

[6] V. Harkava, M. Bezpatochnyi, O. Koshchii, L. Hryshyna, "Formation of a System of Indicators of Assessment of Economic Security of Regions", Estudios de Economia Aplicada, 2021, vol. 7(39). DOI: 10.25115/eea.v39i7.4936

[7] M.N. Rudenko, "Development of a sustainable mechanism for the economic security of the region", Rivista di Studi sulla Sostenibilita, 2020, vol. 2, pp. 33-47. DOI: 10.3280/RISS2020-002-S1004

[8] S.S. Golubev, V.D. Sekerin, A.E. Gorokhova, S.V. Bank, "Problems of economic security in the arctic region", Journal of Environmental Management and Tourism, 2019, vol. 7(10), pp. 1495-1508. DOI: 10.14505/jemt.v10.7(39).07

[9] E.M. Klyuchnikova, L.G. Isayeva, V.A. Masloboev, et al., "Future narratives for key sectors of the economy of the Murmansk region in the context of global changes in the Arctic", The Arctic: ecology and economy, 2017, vol. 1(25), pp. 19-31. (In Russ).

[10] R. Badylevich, M. Ulchenko, D. Kondratovich, "Specific nature and prospects of using integral methods of economic security assessment for the arctic regions of Russian Federation", GÊNERO \& DIREITO, 2020, vol. 4(9). DOI: 10.22478/ufpb.2179-7137.2020v9n04.52846 